\title{
A PRODUÇÃO DE AUDIOVISUAIS COMO NARRATIVA DE CONSTRUÇÃO DO CONHECIMENTO CIENTÍFICO E DE EMANCIPAÇÃO SOCIAL: A EXPERIÊNCIA DA TV LEPETE
}

AUDIOVISUAL PRODUCTION AS A NARRATIVE FOR THE CONSTRUCTION OF SCIENTIFIC KNOWLEDGE AND SOCIAL EMANCIPATION: THE LEPETE TV EXPERIENCE

\section{EM LA PRODUCCIÓN AUDIOVISUAL COMO NARRATIVA PARA LA CONSTRUCCIÓN DEL CONOCIMIENTO CIENTÍFICO Y LA EMANCIPACIÓN SOCIAL: LA EXPERIENCIA LEPETE TV}

Eglê Betânia Portela Wanzeler ${ }^{1}$ Maria Quitéria Afonso Menezes ${ }^{2}$

\section{RESUMO}

O presente artigo tem como finalidade refletir sobre o percurso realizado pelo grupo de pesquisa Lepete (Laboratório de Ensino, Pesquisa e Experiências Transdisciplinares em Educação) da Universidade do Estado do Amazonas, em torno da criação de um canal de TV no YouTube, a TV Lepete. Trata-se de refletir sobre o papel das TIC's no processo de divulgação e comunicação científica, bem como enquanto ferramentas capazes de produzir e gerar novos conhecimentos. A criação do canal se circunscreve numa dimensão política, cuja intenção é promover a disseminação científica, visando à sua popularização e à democratização do conhecimento, enquanto ferramenta de emancipação e de cidadania social.

PALAVRAS-CHAVE: Linguagem digital. Vídeografia. Mediação. Educomunicação. Audiovisuais. Complexidade. Transdisciplinaridade.

\section{ABSTRACT}

This article entitled has as purpose reflect about the made route by the research group Lepete (Laboratório de Ensino, Pesquisa e Experiências Transdisciplinares em Educação) of Universidade do Estado do Amazonas, through the creation of a YouTube Channel, the TV Lepete. It is a reflection of the role of TICs in the process of

Submetido em: 17/07/2020 - Aceito em: 25/11/2020 - Publicado em: 25/01/2021

${ }^{1}$ Graduada em História pela Universidade Federal de Santa Catarina. Mestre em Natureza e Cultura na Amazônia pela Universidade Federal do Amazonas. Doutora em Ciências Sociais pela Pontifícia Universidade Católica de São Paulo. É professora de História da Educação da Universidade do Estado do Amazonas. Líder do grupo de pesquisa Laboratório de Ensino, Pesquisa e Experiências Transdisciplinares em Educação/Lepete e coordenadora do canal TV Lepete.

${ }^{2}$ Graduada em Pedagogia pela Universidade Federal do Amazonas. Mestre em Educação pela Universidade Federal do Amazonas. Professora do Curso de Pedagogia da Universidade do Estado do Amazonas. Vice-líder do Grupo de Pesquisa Laboratório de Ensino, Pesquisa e Experiências Transdisciplinares em Educação/Lepete. 
disseminating and scientific communication, as well as the tools capable of produce new knowledges. The channel criation is made in a political dimension, which the intention is to promote the scientific dissemination, aiming at popularization and the knowledge democratization as tool of emancipation and social citizenship.

KEYWORDS: Digital language. Videography. Mediation. Audiovisuals. Complexity. Transdisciplinarity.

\section{RESUMEN}

El presente artículo tiene como finalidade reflexionar sobre el trayecto realizado por el grupo de investigación Lepete (Laboratorio de Enseñanza, Investigación y Experiencias Transdisciplinares enEducación) de la Universidad del Estado de Amazonas, alrededor de la creación de un canal de televisión enYoutube, TV Lepete. Se trata de reflexionar sobre el papel de las TIC en el proceso de divulgación y comunicacióncientífica, y también como herramientas capaces de producir y generar nuevos conocimientos. La creación delcanal se circunscribe a una dimensión política, cuyafinalidad es promover la difusión científica, con vistas a supopularización y a la democratización del conocimiento, como herramienta de emancipación y ciudadanía social.

PALABRAS CLAVE: Lenguaje digital. Vídeografía.Mediación. Audiovisual. Complejidad. Transdisciplinaridad.

\section{A CONSTRUÇÃO DA LINGUAGEM DIGITAL DO LEPETE}

O presente texto tem como finalidade apresentar analiticamente o percurso realizado pelo grupo de pesquisa Lepete (Laboratório de Ensino, Pesquisa e Experiências Transdisciplinares em Educação) da Universidade do Estado do Amazonas, em torno da criação de um canal de TV no YouTube, a TV Lepete, a partir de seus sistemas de referências e das implicações desses sistemas na produção dos audiovisuais.

O Lepete tem como linha de trabalho a formação inicial e continuada de professores e professoras. Esse processo é desenvolvido por meio da pesquisa formação ${ }^{3}$, que é realizada em serviço, tendo a escola com lócus de formação e a universidade como instância mediadora desses processos, potencializando e impulsionando os currículos das escolas em seus cotidianos. São escolas públicas da rede municipal de ensino, situadas em diferentes contextos: ribeirinha, rodoviária e zona urbana. Em cada escola são criados, por meio da pesquisa-ação colaborativa, projetos de formação oriundos das demandas e necessidades definidas pelos sujeitos escolares. Em outras palavras, os projetos de formação das escolas são principiados pela democracia e pelo respeito as culturas escolares, com suas especificidades e demandas emergentes.

A proposta do canal surgiu da necessidade de divulgação dos trabalhos desenvolvidos por este laboratório no que tange à pesquisa, ao ensino e à extensão, bem como de valorização dos saberes da docência produzidos no campo escolar. Não obstante, a ideia do canal se

\footnotetext{
${ }^{3}$ Pesquisa formação ao qual nos referimos encontra-se ancorada na pesquisa-ação colaborativa, que ocorre durante o processo formativo realizado pelo Lepete.
} 
circunscreve numa dimensão política cuja intenção é promover a disseminação científica, visando à sua popularização, o seu descentramento e a democratização do conhecimento, enquanto ferramenta de emancipação social e de cidadania. A TV Lepete é um canal de comunicação digital de largo alcance social, que se vale da tecnologia do streaming (tecnologia de envio e transferências de dados via web ou internet e de forma rápida) permitindo aos usuários baixar e reproduzir mídias, tais como: filmes, documentários, vídeos e jogos.

O mundo contemporâneo vem apresentando traços cada vez mais acentuados quanto ao uso das tecnologias da informação e da comunicação/TICs, fruto do avanço da ciência e da tecnologia. Um processo que vem atingindo de forma expressiva a sociedade como um todo. A internet, as redes sociais, weblogs e as mídias digitais integram esse sistema de informação e comunicação, produzindo novas narrativas do ser, viver, estar, fazer, sentir e pensar no mundo e sobre o mundo, no qual os limites entre o que somos e o que queremos ser, apontam a fragilidade da condição humana e colocam em xeque os territórios de nossas existências, com nossas individualidades, identidades e subjetividades.

Nesses velhos e novos sistemas-mundos, constituídos de identidades esquizos (impregnadas de permanências e notadamente móveis) e de reconceptualizações culturais e midiáticas, a vida humana segue entre o real e o virtual, entre a vontade do ser, de ser e ser, querer e poder, saber e não-saber, entre a verdade, a mentira e a pós-verdade. O que a ciência tem a ver com isso? É possível uma nova narrativa de comunicação e informação científica a partir das linguagens midiáticas contemporâneas? Como produzir uma narrativa científica por meio de audiovisual, considerando as novas temporalidades, traduzidas por uma nova compreensão do tempo e pela multiplicidade de lugares? A apropriação da linguagem audiovisual representa de fato uma nova forma de resistência frente ao mundo globalizado?

\section{VÍDEOPOESIA: NARRATIVAS DIGITAIS, SABERES DIAGONAIS}

A criação da TV Lepete surge da necessidade de, não apenas, divulgar as ações do grupo de pesquisa, ensino e extensão, de forma mais ampla e de largo alcance social, mas de se colocar como um canal de educação e comunicação capaz de conscientizar as pessoas da importância do conhecimento como instrumento de emancipação e de luta social, contrapondo-se àquela narrativa destrutiva e alienante presente nas redes sociais e nas mídias digitais. Porém não se trata de narrar a realidade em si, ou o que se é produzido pelo Lepete, mas de criar novos mundos, novas narrativas movidas pela potência criativa e imaginária, uma forma de expressão do pensamento, mas precisamente um modo de recognição (DELEUZE, 2006). Isto se dá porque o processo de tradução das experiências de formação e de pesquisa produzidas nas 
escolas em audiovisuais, gera outra forma de pensar e de produzir conhecimento, porque a apreensão da realidade é sempre um modo de tradução e de interpretação. Apesar de estarem implicados entre si, possuem modos de produzir e de pensar diferentes. No entanto, os audiovisuais devem dar significado as experiências nas escolas, mas ao mesmo tempo, fazer com que essas experiências sejam compreendidas em seus significados, imaginários e representações de si mesmas.

A TV Lepete apresenta em seu escopo uma linha editorial cuja finalidade está em promover a disseminação e a popularização da ciência a partir do uso das Tecnologias de Informação e Comunicação/TICs, mais precisamente a partir da produção de audiovisuais, cujos objetivos são: a) contribuir para o processo de democratização do conhecimento científico e cultural, a partir do conjunto de experiências do Lepete e de outras redes de formação, com vista à emancipação da sociedade; b) promover a aproximação entre a ciência e a sociedade, por meio de diálogos transdisciplinares e transculturais, visando a uma relação mais solidária e sustentável quanto ao processo de produção do conhecimento; c) divulgar a produção e construção do conhecimento científico e cultural visando à sua popularização, bem como à viabilização da democracia cognitiva e d) socializar as experiências do Lepete enquanto política de formação, de pesquisa e de responsabilidade socioeducativa.

Mas como produzir audiovisuais que represente o sistema de referências teórico, epistemológico e metodológico deste laboratório? Que formato seria capaz de dar conta de todo o trabalho desenvolvido pelo grupo? Como pensar uma linguagem audiovisual voltada para mídias sociais de forma a atender os princípios teóricos, metodológicos e políticos do projeto TV Lepete?

O Lepete se baseia epistemologicamente no pensamento complexo e na transdisciplinaridade. Trata-se de uma visão de ciência libertária e consciente diante de um mundo permeado por conflitos econômicos, etnicoculturais, religiosos, éticos, políticos e sociais, bem como por problemas de natureza ecológica e ambiental, que ameaçam o equilíbrio do mundo e a sobrevivência planetária. A atitude transdisciplinar, como princípio norteador para produção de audiovisuais da TV Lepete, recoloca a ciência como lugar que produz experiências sociais, uma aventura humana nos caminhos da descoberta, do conhecimento e de transformação social. O próprio prefixo trans, que significa aquilo que está entre as disciplinas, através das disciplinas e para além das disciplinas (NICOLESCU, 2000), indica a relação da ciência com toda sua dimensão humana. Mas o que está dentro e ao mesmo tempo atravessa a ciência e o que parece estar além dela? Acreditamos ser a arte, enquanto experiência que representa um elo de significação do sentido da transdisciplinaridade, pois por ela é possível a conexão entre ciência e sociedade, uma vez que é a tradução estética e cultural do fazer científico. A arte audiovisual, 
nesse caso, seria o elemento mediador entre aquilo que é produzido pelo Lepete, com seus modos de saberesfezeres, sentirpensar, e a sociedade.

A complexidade, principiada como fundamento do trabalho da TV Lepete, representa a possibilidade de uma visão transdisciplinar sobre aquilo que é produzido pela ciência, no campo das licenciaturas, mas também de outras áreas de conhecimento da Universidade do Estado do Amazonas e suas relações com a sociedade, a partir de suas multireferencialidades. Para Morin (2001), a complexidade é entendida como um tipo de pensamento que não apenas separa, mas une e busca as relações necessárias e interdependentes de todos os aspectos da vida humana, integrando os diferentes modos de pensar.

A complexidade procura estabelecer as relações entre cada fenômeno e seu contexto, a reciprocidade entre o todo e as partes; perceber como uma determinação local repercute sobre o todo e como uma modificação do todo repercute sobre as partes. A produção de audiovisuais é sem dúvida uma ferramenta de articulação e mediação entre as partes e o todo, assegurando a construção de saberes diagonais, ou de epistemologias transversais.

Para Bachelard (2004) a aproximação entre o conceito e a experiência é fator primordial para a produção do conhecimento. Um processo que se dá partir da organização dos centros de referencias nos quais os dados são percebidos e experienciados no interior da teoria e se constroem a partir dos diferentes modos de viver, pensar e sentir. Os audiovisuais produzidos pela TV Lepete são feitos a partir da inclusão das experiências do grupo no processo de compreensão e descrição do conhecer e de sua tradução em imagem. Essa descrição é feita pelo impulso intuitivo recebido num instante em que experiência e sentido se amalgamam dando unidade ao conhecimento videográfico.

A partir dos estudos semióticos baseados em Charles Peirce (1999) o projeto TV Lepete se propõe como uma comunidade de conhecimento e de aprendizagem capaz de conduzir homens e mulheres a refletirem sobre si mesmos/as, uma vez que permite uma melhor compreensão das diferentes interfaces das linguagens audiovisuais, em diálogo com a escola, na medida em que têm nos signos os elementos de percepção, representação e de conhecimento, por meios dos quais a realidade é significada, interpretada e os sentidos são produzidos signicamente.

Para os estudos do regime dos signos audiovisuais, numa perspectiva transdisciplinar, a semiótica nos garante, em larga medida, uma sofisticada aproximação e articulação entre a forma como produzimos os programas e os sentidos que queremos dar ao produto, bem como entre a leitura, o leitor, a informação, comunicação e conhecimento, a partir da apreensão da diversidade linguística e de seus múltiplos códigos. 
Com efeito, a produção de mídias alternativas para divulgação e comunicação científica, exige uma ruptura com os modelos tradicionais de divulgação cientifica. Em tempos contemporâneos é preciso assumir o desafio que as redes sociais impõem à informação e ao conhecimento, que de forma acelerada atinge a população em tempos reais. Portanto, é preciso construir ferramentas capazes de nivelar as diferentes linguagens que vem sendo veiculadas na internet e que garantam uma percepção e significação científica e cultural daquilo que é produzido pela universidade e em outras instituições da sociedade.

Os audiovisuais relacionam infinitas possibilidades de articulação entre do som e a imagem, refletindo a pluralidade de pensamento, que nesse projeto assume uma natureza ensaística e poética, uma escrita digital didática e pedagógica, que denominamos de vídeopoesia. Além disso, a escrita audiovisual da TV Lepete expressa uma nova narrativa da ciência, desterritorializando o conhecimento, ao mesmo tempo criando novos territórios e ou reterritórios de produção de conhecimento aliado a uma perspectiva inclusiva, pois permite ampliar o acesso das pessoas de forma democrática, de fácil compreensão, uma vez que produz um tipo de narrativa articulada ao pensamento e linguagem, imagem, escrita e som. Um olharvídeo sobre o conhecimento desterritorializado e ou reterritorizado, visto que se impõe como novo, mas se alimenta do que vê, lê, sente, pensa e age (GUATARRI, 1982).

Importante destacar, como nos lembra Morin (2002), que a cultura, veículo cognitivo da linguagem, gerada/geradora de conhecimento, transforma aquilo que é invisível em visível, tátil, por meio de confrontos, trocas de ideias, teorias, sentimentos, desejos, intuições, subjetividades e concepções, que se dá por meio de interações recíprocas dos sujeitos entre si com os objetos e seus mundos. Cultura se constitui como experiência capaz de transformar a palavra em ato, nos revelando no e para o mundo, ao mesmo tempo em que permite o mundo nos revelar.

Nesta direção a TV Lepete encontra na Pedagogia do Oprimido de Paulo Freire (1987), os princípios éticos, estéticos e políticos que orientam suas produções, uma vez que entende que o conhecimento é fonte, caminho, ferramenta, estratégia de libertação e de emancipação social. Para Freire a Pedagogia do Oprimido é:

\footnotetext{
aquela que tem de ser forjada com ele e não para ele, enquanto homens ou povos, na luta incessante de recuperação de sua humanidade. Pedagogia que faça da opressão e de suas causas objeto da reflexão dos oprimidos, de que resultará o seu engajamento necessário na luta por sua libertação, em que esta pedagogia se fará e refará. (FREIRE, 1987, p.17)
}

Os audiovisuais da TV Lepete são construídos e ou forjados na e pela luta de produzir uma linguagem digital que expresse imagética e simbolicamente a produção científica de um grupo de pesquisa, ensino e extensão, mas fundamentalmente que produza uma relação de 
reciprocidade entre ciência, educação e sociedade, como uma experiência democrática cognitiva e socialmente referendada.

\section{FORMAÇÃO E COMUNICAÇÃO: A TV LEPETE E A CRIAÇÃO DE UM NOVO ECOSSISTEMA COMUNICACIONAL}

Inicialmente a proposta do canal era produzir registros videográficos sobre os modos de saberesfazeres do Lepete em seus cotidianos, mas nos demos conta que ao produzirmos os audiovisuais estávamos na verdade construindo novos modos de construção de conhecimento e de percepção sobre nós mesmos, abrindo espaços para novas experiências, novas subjetividades, novos espaços de sociabilidades, contribuindo para a criação de um ecossistema comunicativo (MARTÍN-BARBERO, 1997) nutrido por novos modos de ler, ver, sentir, pensar e aprender, a partir daquilo que produzimos nos cotidianos escolares, na universidade, e isto inclui vivências culturais, experiências científicas, conhecimentos e práticas curriculares.

Os audiovisuais da TV Lepete são produzidos por uma equipe multidisciplinar, composta por produtores, estagiários das áreas da comunicação, jornalismo, designer gráfico e publicidade, além de estudantes das áreas de letras e de pedagogia. Todo o processo de produção da TV é feito a partir das seguintes etapas:

1) Pré-produção: etapa voltada para: a) definição da pauta; b) pesquisa de conteúdos; c) estudos sobre a temática; d) roda de conversa sobre os marcos conceituais e metodológicos a serem utilizados para a narrativa; e) definição dos personagens, lugares para filmagem; f) criação do roteiro e g) elaboração do cronograma de filmagens e de pós-produção;

2) Produção: etapa em que são feitos os registros fílmicos, na qual é realizado a captação em áudio e vídeo de depoimentos e entrevistas, bem como imagens de apoio;

3) Pós-produção: etapa em que se dá a montagem dos produtos audiovisuais e passa pela: a) finalização de cor e som dos produtos audiovisuais; b) análise do produto final e c) lançamento no canal no YouTube.

Os produtos audiovisuais produzidos pela TV Lepete são de caráter jornalístico e algumas produções consideram-se documentários jornalísticos. Desta forma, a linguagem discursiva utilizada nos episódios é marcada pelo olhar e visão do Laboratório de Ensino, Pesquisa e 
Experiências Transdisciplinares em Educação (Lepete), que expõe opiniões e deixa claro para os espectadores o ponto de vista defendido. Todos os episódios possuem um tema em específico que partem de um fato, procuram mapear outros fatos correlacionados, acontecimentos interligados, trazendo consigo o tom de explicação e com a ajuda de uma apresentadora que interliga os fatos, apresentando imagens e depoimentos que significam o que é dito.

Dessa forma, os episódios são produzidos por meio de captação de áudio e vídeo de depoimentos e imagens de apoio, utilizando de som direto, de forma que funcionem como documentos e evidenciação de recortes da realidade, além do uso de som síncrono com trilhas sonoras em momentos específicos, adicionadas na montagem. Portanto, no processo de pósprodução todos os depoimentos conversam entre si, há sobreposição de imagens, fotos, vídeos, etc. para evidenciar o conteúdo.

O canal se utiliza da plataforma online YouTube para hospedar seus vídeos, tendo ciência da sua responsabilidade socioeducativa. Assim, por meio dos episódios e programas, aproximamse ciência e sociedade, independente de idade e cargos sociais, dispondo de experiências transdisciplinares e transculturais, divulgando e popularizando a produção e construção do conhecimento científico e cultural e viabilizando a democracia cognitiva.

As pautas que dão origens aos audiovisuais são geradas das ações realizadas pelo Lepete, a partir de seus projetos de pesquisa, ensino e de extensão que destacamos: o Projeto OFS (Oficinas de Formação em Serviço), destinado a formação continuada de professores/as que ocorre em escolas da rede municipal de ensino; o Projeto Assistência a Docência, voltado para formação inicial de professores/as e também tem a escola como lugar de profissionalização docência. Em tese esses dois projetos constituem-se como pautas centrais que marcam a trajetória videográfica do canal e conta um pouco da história do Lepete enquanto grupo de pesquisa.

A tradução das experiências do Lepete para audiovisuais, implicou em processos reinterpretativos sobre o grupo, o que só foi possível com a criação desse ecossistema comunicativo, entendido por um conjunto de ações voltadas para promoção da difusão, disseminação e popularização da ciência, produzindo novos conhecimentos, ampliando as relações de comunicação entre a ciência e a sociedade, descentralizando o poder, tirando do centro a academia, ao tempo que estimula novos diálogos, novas interações, abrindo espaços para novas experiências e vivencias culturais mais democráticas e cidadã. 


\section{CONSIDERAÇÕES: CARTOGRAFIA DIGITAL E A LINGUAGEM VIDEOGRÁFICA DO LEPETE}

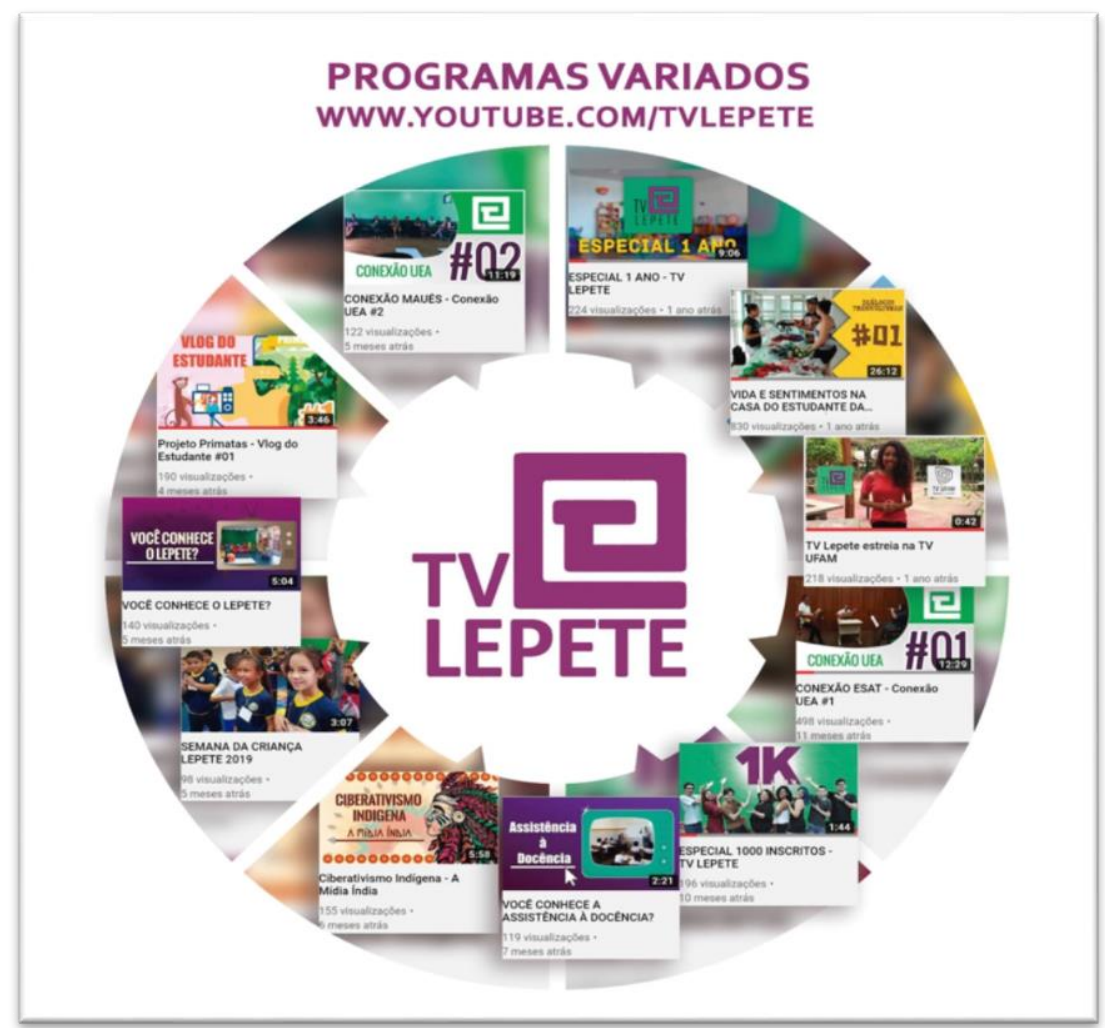

Figura 7 - Cartografia Digital 6: mostras de produtos audiovisuais da TV Lepete. São audiovisuais produzidos para além das atividades do Lepete. Fonte: equipe de comunicação do Lepete.

O Canal produziu, desde de sua criação em 2017, quarenta produtos audiovisuais (que podem acessados pelo link: www.youtube.com/tvlepete) organizados a partir da seguinte cartografia digital:

- Episódios Lepete: Série destinada a divulgação dos projetos de pesquisa, ensino e extensão do próprio Lepete, com destaque para as Oficinas de Formação em Serviço e Assistência à Docência;

- Saberes e Dicas: é uma série com dicas para quem vai prestar concurso na área de magistério/educação; 
- Teses \& Ideias: visa transformar o trabalho científico, tese ou dissertação, escolhido pelo seu grau de relevância e impacto social, em vídeo documentário. Tem como etapa de produção o Circuito Teses \& Ideias, no qual o autor da tese ou dissertação participa de uma entrevista, falando sobre seu processo de construção de conhecimento. A gravação do Circuito é aberta ao público. Trata-se de divulgar a produção científica desenvolvidas pelos professores e professoras, visando sua popularização e disseminação, consolidando dessa maneira a democracia cognitiva.

- Clipping UEA: um programa de aproximadamente 1min que divulga os ventos que acontecem na UEA;

Além desses programas o canal produz outros audiovisuais com formatos documentais de média e longa duração, além de pequenos vídeos voltados para divulgação de eventos ou curiosidades sobre o Lepete, que abaixo apresentamos:

- Conexão UEA: É um programa que populariza e divulga as ações e projetos de extensão, pesquisa e ensino dos centros, unidades e núcleos da UEA e suas implicações nas melhorias da qualidade de vida e na aplicação e transferência de conhecimento técnico-científico.

- Diálogos Transculturais: é um documentário de até 30 minutos que aborda questões sociais e culturais, voltado para temáticas contemporâneas como: identidade, cultura, gênero e movimentos sociais. Seu intuito é aproximar a universidade da sociedade, fazendo com que haja o fortalecimento de uma cultura de comunicação digital regida pela ética e pelo compromisso;

- Minuto Lepete - É uma chamada de cada programa da TV Lepete para o facebook e demais redes sociais, que tem como objetivo ampliar o alcance do canal, aumentando também o número de assinaturas.

- Momento Lepete - É uma entrevista simples para fins de divulgação de algum evento ou projeto do Lepete ou da UEA, que esteja acontecendo no momento, objetivando levar ao conhecimento do público o que é realizado nos projetos e eventos.

A escrita eletrônica ou digital da TV Lepete se circunscreve como uma experiência que produz conhecimento, mas principalmente produz cultura, linguagem videográfica. Neste termos, os audiovisuais, são sistemas autopoiéticos (MATURANA e VARELA, 1997), produzem a si mesmo, e, enquanto experiência da cultura, representam a diversidade do olhar-vídeo, marcas dos territórios existenciais, sistemas de referencias do laboratório. Um processo que não apenas desterritorializa os espaçostempos de produção, como cria novos modos de produção de 
conhecimento, em novos espaçostempos, nesse caso, o ecossistema comunicativo, e, fundamentalmente, descentraliza os sabereslugares de poder.

Valendo-nos de Martín-Barbero (2003), compreendemos que os audiovisuais produzidos pela TV Lepete são espaços de mediações, nos quais conhecimento, ciência, pensamentos, ideias circulam entre si e dão sentido, significações aos novos modos de produção do laboratório, materializados na linguagem digital, sob forma de narrativa videográfica. Os lugares de mediações dos quais são gerados os audiovisuais encontram-se imbricados nos modos de saberesfazeres dos e nos cotidianos do grupo, com suas temporalidades e suas subjetividades, dos quais são ancorados os sistemas de referencias epistemológicas, teóricas, culturais (materiais e imateriais), sociais, cognitivas, políticas e pedagógicas do laboratório em suas relações com as escolas no tripé ensino, pesquisa e extensão.

Valorizar a produção do conhecimento cientifico e cultural produzida pelos/as professores/as pesquisadores/as das instituições de ensino superior e da educação básica constitui-se como ação de políticas públicas de grande relevância social, mas é importante que esta produção atinja a sociedade, contribuindo para um mundo menos desigual, mais humano e solidário. A TV Lepete representa um lugar de experiências da democracia cognitiva, cumprindo com uma função primordial da ciência: promover e garantir o bem-estar social a partir da igualdade de acesso ao conhecimento pertinente e a informação crítica e libertária.

\section{REFERÊNCIAS}

BACHELARD, G. Ensaio sobre o conhecimento aproximado. Tradução de Estela dos Santos Abreu. Rio de Janeiro: Contraponto, 2004.

DELEUZE, G. Diferença e Repetição. Trad. Luiz Orlandi e Roberto Machado. Rio de Janeiro: Grall 2006.

FREIRE, P. Pedagogia do oprimido. Rio de Janeiro: Paz e Terra, 1970.

GUATARRI, F. Caosmose: um novo paradigma estético. Rio de Janeiro: Editora 34, 1992.

GUATARRI, F As três Ecologias. Tradução de Maria Cristina F. Bittencourt. Campinas, SP: Papirus, 1990.

MARTÍN-BARBERO, J. Dos meios às mediações. Comunicação, cultura e hegemonia. Rio de Janeiro: UFRJ. 1997.

MARTÍN-BARBERO, J. Dos meios às mediações. Rio de Janeiro: Editora da UFRJ, 2003. 
MATURANA, H. e VARELA F. De máquinas e seres vivos: autopoiese - a organização do ser vivo. 3a ed. Tradução de Juan Acña Llorens. Porto Alegre: Artes Médicas, 1997.

MORIN. E. Ciência com Consciência. Tradução de Maria D. Alexandre e Maria Alice São. Ed. Revista e ampliada pelo o autor. 5 ${ }^{\text {a }}$ ed. Rio de Janeiro: Bertrand Brasil, 2001.

MORIN. E. O Método 5. A identidade humana. A humanidade da humanidade; Tradução de Juremir Machado da Silva. Porto Alegre: Sulina, 2002.

NICOLESCO, B. O Manifesto da Transdisciplinaridade. Tradução de Lúcia Pereira de Sousa. São Paulo: Triom, 2000.

Este é um artigo de acesso aberto distribuído sob os termos da Licença Creative Commons Atribuição Não Comercial-Compartilha Igual (CC BY-NC- 4.0), que permite uso, distribuição e reprodução para fins não comerciais, com a citação dos autores e da fonte original e sob a mesma licença. 